SHORT REPORT

\title{
Accounting for the social disparity in birth weight: results from an intergenerational cohort
}

\section{N Spencer}

S ocial disparity in birth weight is well recognised ${ }^{1}$ but less well explained. Maternal height, smoking, substance misuse, and micronutrient deficiency are the most likely determinants of social disparities in birth weight. ${ }^{1}$ Intergenerational effects through maternal birth weight and growth in early childhood have also been suggested as mediators of social difference in birth weight. ${ }^{23}$ This paper uses data from the 1958 British national birth cohort to study variables, originating at different stages in the maternal life course, that may mediate the disparity in birth weight.

\section{PARTICIPANTS, METHODS, AND RESULTS}

I undertook secondary analysis of data on first reported pregnancies ending in live, singleton births to female members of the 1958 British national birth cohort $^{4}$ up to age 33 years. Gestation ( $<37$ weeks versus $37+$ weeks), daily cigarette smoking in pregnancy (none;0-9;10-19;20-29;30$39 ; 40+$ ) and infant birth weight (g) were collected at the sweep following birth. Maternal height (metres) and adult social class (highest occupation woman/partner categorised into I,II,IIIn-m,IIIm,IV,V) were collected at age 23. Social class of origin (father's occupation) and maternal birth weight were collected at her birth. Manual social class groups reduced from $77 \%$ to $55.8 \%$ between the generations. I regressed birth weight on social class at 23 adding potential mediators of birth weight disparity in order from pregnancy to intergenerational factors and in reverse order. Plotted residuals met the normality assumptions for linear regression. As there were no significant interaction effects of social class at 23 with other independent variables, interaction terms were omitted. Women with incomplete data were excluded. Missing height, gestation, and social class at 23 accounted for $>90 \%$ of incomplete data.

Of 3805 women with singleton live births, 2747 (72\%) had complete data. Birth weight reduced by $42.6 \mathrm{~g}$ for every decline in social class. Pregnancy factors (gestation and smoking) accounted for $10.7 \mathrm{~g}$ of the disparity and intergenerational/early childhood factors (maternal birth weight/social class at birth and maternal height) accounted for a further $10.3 \mathrm{~g}$. Reversing the order did not change

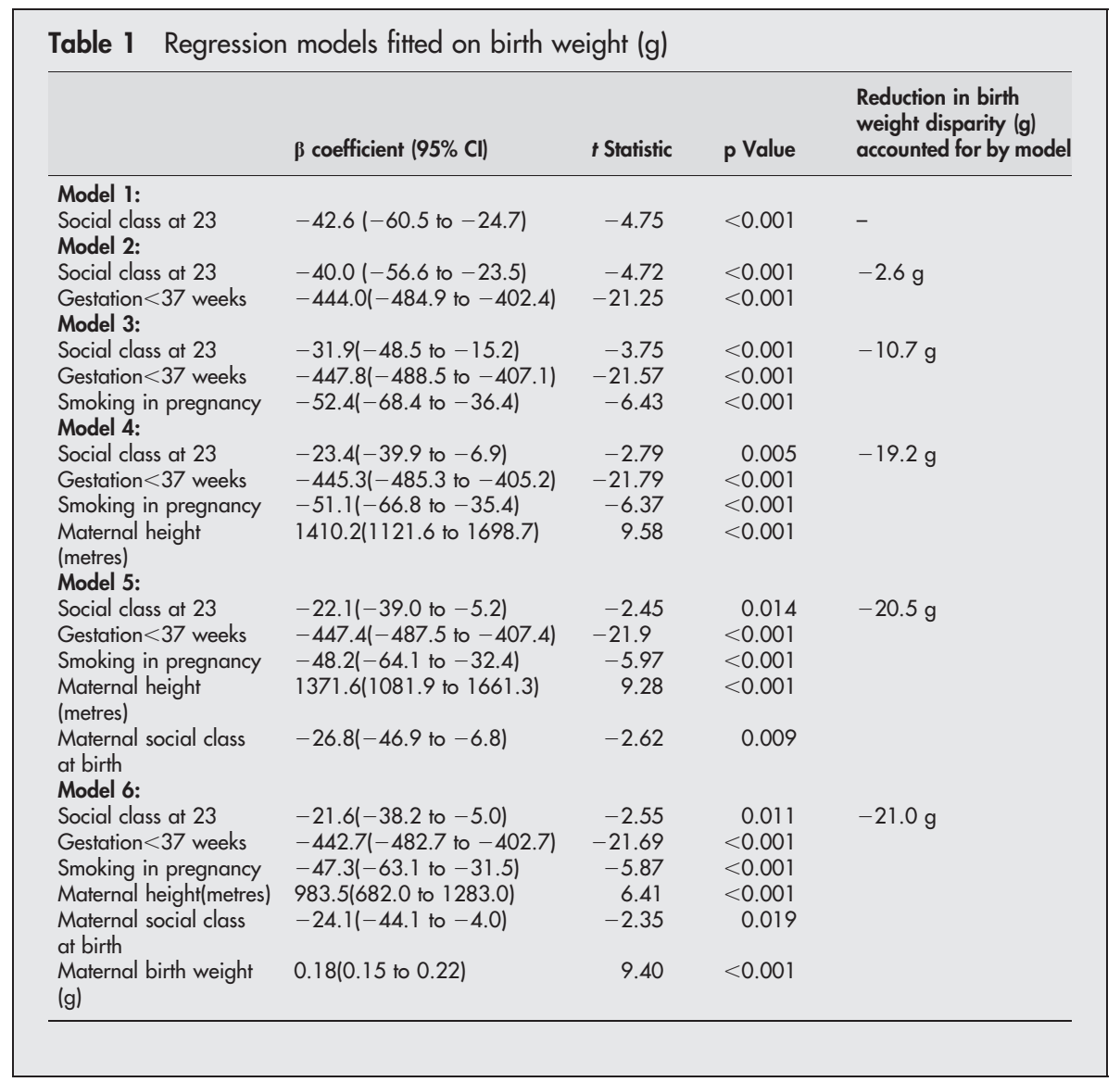


the birth weight difference explained by each group of factors (table 1).

\section{COMMENT}

Intergenerational and early childhood factors accounted for $10.3 \mathrm{~g}$ of the birth weight disparity between social classes. Factors operating in the pregnancy itself accounted for 10.7 g. Smoking alone accounted for $8.1 \mathrm{~g}$ of the difference. Similar results were reported from a longitudinal study of Aberdeen school children. ${ }^{3}$ In a study of Swedish singleton births in 1985, ${ }^{5}$ age, parity, and gestation had little effect on social disparity. Adding maternal height and smoking eliminated the social differences. The smaller social disparity in the Swedish study (94 g over the whole social class range) may account for the contrasting results.

Applicability of my findings to current social disparities in birth weight is open to challenge. The births studied occurred between 12 and 25 years ago and determinants of social disparity may have changed. Changes in the prevalence of risk factors are likely to have affected their impact on the social disparity. Differential reduction in pregnancy smoking prevalence by social class may have increased the relative importance of smoking in accounting for the birth weight disparity. Differential social attrition may have biased the distribution of factors determining the disparity although, as a result of greater loss of women in the lower social classes, bias in the direction of underestimating early social class effects on birth weight was likely.

My findings show that social differences in birth weight are determined not only by socially patterned health related behaviour in pregnancy but also by the effect of intergenerational and early childhood social circumstances on fetal and early childhood growth. Poor social circumstances transmit intergenerational adverse effects through an impact on early growth possibly through a combination of fetal programming and direct adverse effects on growth in infancy.

\section{ACKNOWLEDGEMENTS}

I thank the UK Data Archive, University of Essex for their kind permission to use the NCDS dataset.

Funding: none.

Conflicts of interest: none declared.

N Spencer, School of Health and Social Studies and Warwick Medical School, University of Warwick, Coventry CV4 7AL, UK;

n.j.spencer@warwick.ac.uk

Accepted for publication 10 December 2003

\section{REFERENCES}

1 Kramer MS, Séguin L, Lydon J, et al. Socio-economic disparities in pregnancy outcome: why do the poor fare so poorly? Paediatr Perinat Epidemiol 2000;14:194-210

2 Joffe M. Social inequalities in low birth weight: timing of effects and social mobility. Soc Sci Med 1989;28:613-19.

3 Morton SM, Leon DA, De Stavola BL, et al. Transgenerational influences on inequalities in size at birth. [Abstract]. J Epidemiol Community Health 2000;54:774.

4 Ferri E. Life at 33: the fifth follow-up of the national child development study. London: National Children's Bureau, 1993.

5 Vågerö D, Koupilová I, Leon DA, et al. Social determinants of birthweight, ponderal index and gestational age in Sweden in the 1920s and the 1980s. Acta Paediatr Scand 1999;88:445-53. 